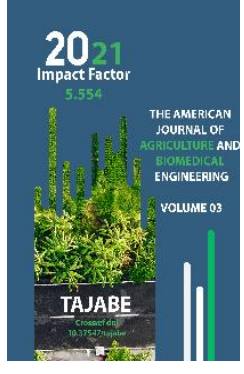

Journal Website: https://theamericanjou rnals.com/index.php/ta jabe

Copyright: Original content from this work may be used under the terms of the creative commons attributes 4.0 licence.

\section{Colorado Beetle And Potential In Potatoes Effective Struggle}

\author{
Dilshod Obidzhanov \\ Doctor Of Philosophy Of Agricultural Sciences (PhD), Scientific Research Institute Of HV And \\ V Named After Academician M.Mirzaev, Uzbekistan
}

\section{Shokir Zokirov}

Doctoral Student, Uzbek Research Institute Of Plant Protection, Uzbekistan

Kholbek Erkinov

Magistr, TashDAU, Uzbekistan

\title{
ABSTRACT
}

In the climatic conditions of Uzbekistan, the lack of agro-technical and chemical measures against the Colorado potato beetle will cause significant damage to potato yields. If Colorado potato beetle larvae and beetles appear in the potato field, one of the following insecticides can be used successfully, considering other pests at once: Dalate-Plus, 10\% e.k. - 0,05 l/ha, Deluxe Ultra, 10\% e.k. $0,035 \mathrm{l} / \mathrm{ha}$.

\section{KEYWORDS}

Potato, Plant Protection, Pest, Colorado Potato Beetle, Potato Moth, Biological Features, Insecticides, Efficiency, Measures Of Control.

\section{INTRODUCTION}

The steady growth of the population of Uzbekistan requires the rational use of available land, high yields on the basis of intensive technologies and a steady increase in food production. One of the main tasks in this regard is to protect agricultural crops, including potatoes, from pests and diseases. 
Potatoes are severely damaged by a number of pests, and if timely chemical control measures are not taken against them, the yield of potatoes will be sharply reduced. Worldwide, $6-6,5 \%$ of the potato crop is killed by pests each year [1].

The Colorado potato beetle is one of the pests that causes great damage to potato yields in the Republic.

Colorado potato beetle - Leptinotarsa decemlineata Say. Beetles - Coleoptera family, leaf rodents Chrysomelidae family.

Colorado potato beetles overwinter in the soil to a depth of $20-60 \mathrm{~cm}$. In the spring, when the ground temperature warms up to $14-15^{\circ} \mathrm{C}$, the beetles begin to fly. After additional feeding, the insects hatch and the female beetles lay 1280 eggs in clusters under the leaves of the herbaceous plants (Fig. 1). The average beetle can lay 400-700 eggs, up to a maximum of 2400 (Pospelov, 1978). The larvae fall to the ground and turn into a fungus at a depth of 5-15 cm. In our region, the Colorado potato beetle develops by giving 3-4 generations per year. The reason is that during the hot summer days of the republic, this insect goes into the

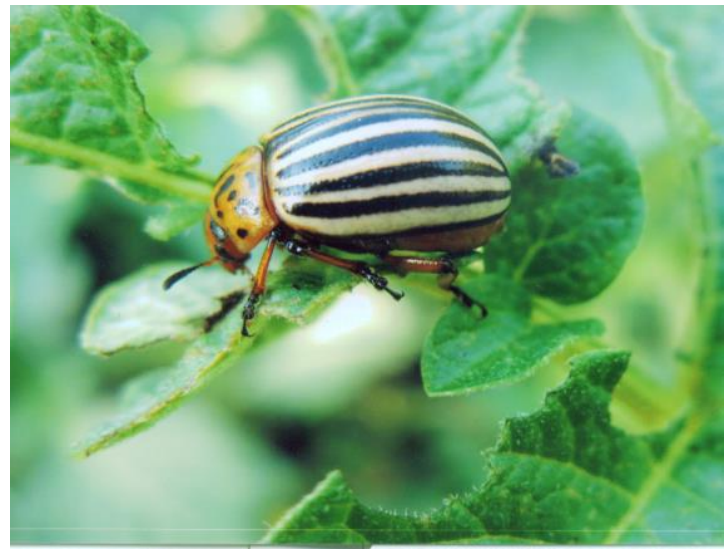

1 summer diapause. The frost resistance of the Colorado potato beetle is not very high. In experiments, $50-100 \%$ of beetles were killed at $-9-11{ }^{\circ} \mathrm{C}$ for $9 \mathrm{~h}[1]$. Therefore, in the northern regions, up to $85 \%$ of beetles die during the winter in some years. One of the features of the development of the Colorado potato beetle is adaptation to the environment, which is carried out through the diapause $[1,2,4]$. The climatic conditions of the republic are favorable for the development of the Colorado potato beetle. The development of one generation of the Colorado potato beetle is 3550 days in the foothills and 25-45 days in the plains $[1,4,5]$.

In recent years, due to the sharp increase in the damage of the Colorado potato beetle on potato farms in the country and the increased resistance of the Colorado potato beetle to certain drugs, research has been conducted to test new drugs against it due to its phenological development.

Place and technique of researches In our research, generally accepted methods (methods of conducting field experiments and Methodological guidelines) were used [3].

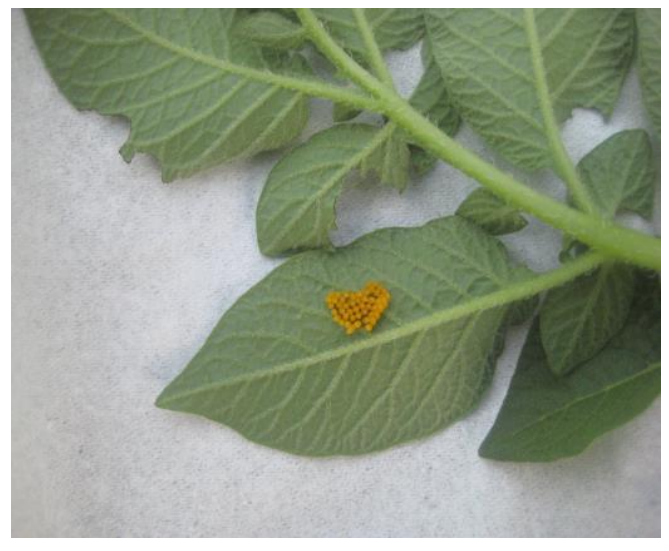

2 


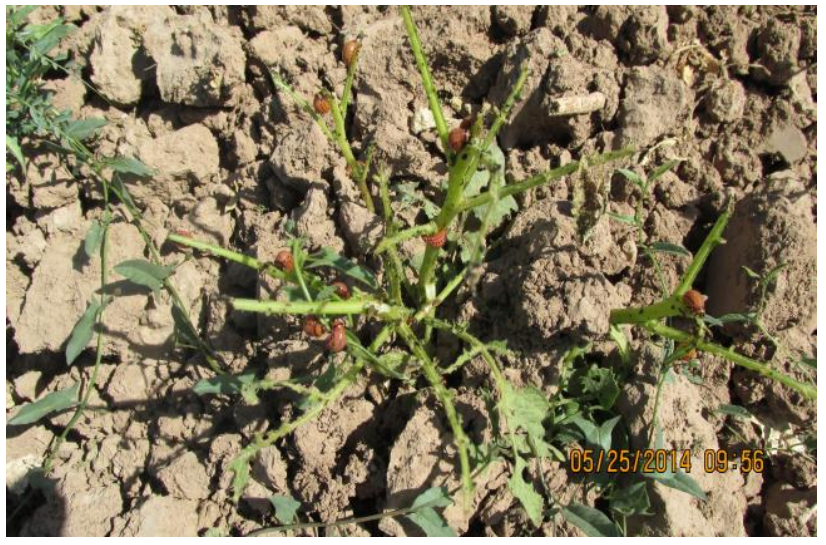

3

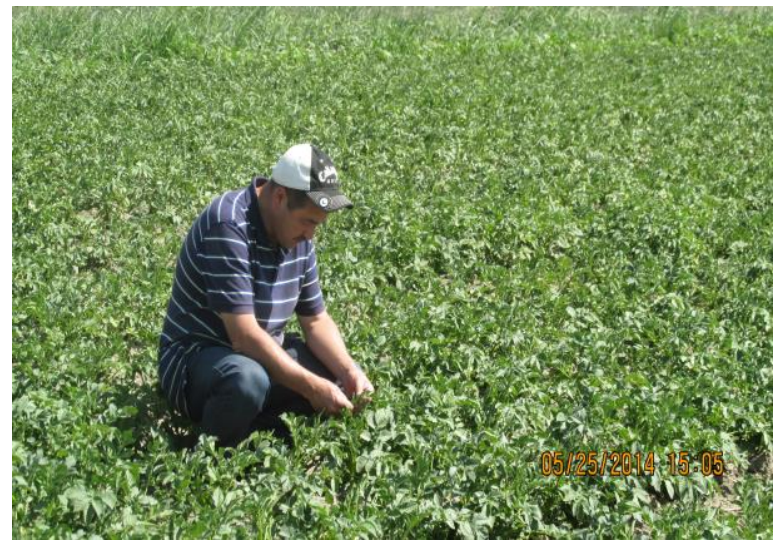

4

Picture. 1 - Colorado potato beetle; 2 - beetle eggs on potato leaves; 3 - adult larvae infect potatoes; 4 - post-defense appearance.

\section{RESULTS OF EXPERIMENTS AND THEIR}

\section{DISCUSSION}

In 2019-2021, we conducted field observations to study the prevalence and infestation of Colorado potato beetle in the potato fields of Samarkand, Tashkent and Fergana regions of the country. Our observations revealed that it affected up to $100 \%$ of some potato fields, with an average of 8,6-21,5 pieces per potato plant in these areas.

Dalate plus against Colorado potato beetle in potatoes, $10 \%$ e.k. 0,05 l/ha., When used in moderation, the efficiency on the 1st day of the calculation was $92,0 \%$ to $94,2 \%$ on the 3 rd day, the efficiency on the 7 th day was $95,3 \%$, the efficiency on days 14-21 was 92,6\%. Deluxe ultra, $10 \%$ e.k. 0,035 l/ha., When used in moderation, the efficiency on the 1st day of the calculation day averaged $98,1 \%$, on the $3 r d$ day $99,0 \%$, on the 7 th day the efficiency averaged $98,1 \%$ and on the 14 th day of the calculation day $96,8 \% . \%$, On the 21st it was 94,9\%. Karate in the template variant, $5 \%$ e.k. When used at a dose of $0,1 \mathrm{l} / \mathrm{ha}$, the efficiency of the 1 st day averaged $90,1 \%$, the 3 rd day $-94,6$, the 7 th day $-96,0 \%$, the 14 th day - 95,1\% and the 21st day efficiency average 94,2\% (Table 1).

1-table

\section{Biological efficacy of Dalate Plus insecticide against Colorado potato beetle in potatoes}

Field experience. Toshkent vil. Kibray t. Yangiabad Kodirov Maksud f / x. 01.06.2021 y.

\begin{tabular}{|c|c|c|c|c|}
\hline \multirow{2}{*}{ Options } & Dori- & \multicolumn{2}{|c|}{$\begin{array}{c}\text { Average number of insects per 1 } \\
\text { plant, pcs }\end{array}$} & \multirow{2}{*}{ Efficiency,\% } \\
\cline { 3 - 3 } & Lar's & & by days: \\
\cline { 3 - 4 } & spend- & & $\begin{array}{c}\text { For the days after } \\
\text { spraying: }\end{array}$ & \\
\hline
\end{tabular}


The American Journal of Agriculture and Boimedical Engineering (ISSN - 2689-1018)

\begin{tabular}{|c|c|c|c|c|c|c|c|c|c|c|c|c|}
\hline & $\begin{array}{c}\text { norm } \\
\text { I/ga }\end{array}$ & $\begin{array}{c}\text { Until } \\
\text { process } \\
\text { ing }\end{array}$ & 1 & 3 & 7 & 14 & 21 & 1 & 3 & 7 & 14 & 21 \\
\hline $\begin{array}{c}\text { Dalate-Plus, 10\% } \\
\text { e.k. }\end{array}$ & 0,05 & 18,8 & 1,5 & 1,1 & 0,9 & 1,4 & 1,4 & 92,0 & 94,2 & 95,3 & 92,6 & 92,6 \\
\hline $\begin{array}{c}\text { Deluxe Ultra, 10\% } \\
\text { e.k. }\end{array}$ & 0,035 & 20,5 & 0,4 & 0,2 & 0,4 & 0,7 & 1,1 & 98,1 & 99,0 & 98,1 & 96,8 & 94,9 \\
\hline $\begin{array}{c}\text { Karate, 5\% em.k. } \\
\text { (default) }\end{array}$ & 0,1 & 22,2 & 2,2 & 1,2 & 0,9 & 1,1 & 1,3 & 90,1 & 94,6 & 96,0 & 95,1 & 94,2 \\
\hline $\begin{array}{c}\text { Control (no } \\
\text { processing) }\end{array}$ & - & 23,8 & 23,8 & 24 & 24,1 & 23,9 & 24 & - & - & - & - & - \\
\hline
\end{tabular}

\section{CONCLUSION}

Based on the results and data obtained from the research, we can conclude as follows.

If agrotechnical and chemical control measures against the Colorado potato beetle are not carried out, it will cause great damage to potato yields.

If the Colorado potato beetle larvae and beetles appear in the potato field, one of the following insecticides can be used successfully, considering other pests at once: Dalate-Plus, 10\% e.k. - 0,05 I/ha, Deluxe Ultra, 10\% e.k. $0,035 \mathrm{l} / \mathrm{ha}$.

\section{REFERENCES}

1. Khojaev Sh.T. Basics of combined plant protection from pests and agrotoxicology. - Tashkent: Navruz, 2014. - 541 p.

2. Cherniy A.M., Chayka V.N., Baklanova O.V. Kontrol chislennosti koloradskogo juka i kartofelnoy moli // J. Zashchita rasteniy. Moscow, 1994. - №5. - S. 7-8.

3. Khojaev Sh.T. Guidelines for testing insecticides, acaricides, biologically active substances and fungicides. Tashkent, 2004. $-103 \mathrm{p}$.

4. Khamrakulova L.P., Toirov M.Z., Agzamova X.K., Arslonov M.T. Recommendations for the effect of Novodor against Colorado potato beetle worms. Tashkent, 1997. - $4 \mathrm{p}$.

5. Obidzhanov D., Erkinov Kh. Potato pests in uzbekistan. // The American Journal of Agriculture and Boimedical Engineering (ISSN - 2689-1018). July 30, 2021. R. 11-20. 